\title{
Composite grouting mortar based on 3D-NKM - nanocrystalline inoculant
}

\author{
Marina Panfilova ${ }^{1, *}$, Nikolay Zubrev ${ }^{2}$, Olga Novoselova $^{1}$, and Sania Efremova ${ }^{3}$ \\ ${ }^{1}$ Moscow State University of Civil Engineering, Yaroslavskoe shosse, 26, Moscow, 129337, Russia \\ ${ }^{2}$ Federal State Budget Educational Institution higher education "Russian University of Transport \\ (MIIT)", ul. Obraztsova, 9, 127994 Moscow, Russia \\ ${ }^{3}$ Penza State Technological University, PenzSTU, travel Baidukova / st. Gagarin, d. 1a/11, 440039, \\ Penza, Russia
}

\begin{abstract}
For the waterproofing of tunnels and the uniform distribution of space between the lining of tunnels and rock, composite injection solutions are used. To improve the physical and mechanical properties of cement composites, the nanoconstruction effect is used, which is possible when using nanoparticles with extended geometry. Nano-additives and nanomodifiers consisting of nanoparticles, both natural and artificial and technogenic, can be used for the production of cement-containing solutions and concretes. For example, under certain conditions nanocrystalline powder of oxides and hydroxides of aluminum to nanotechnogenic raw materials can be referred to wastes of technogenic origin. The paper investigated the effect of nano-additives-boehmite, which is a waste of production, to increase the strength and frost resistance of plugging materials made on the basis of cement when administered. It is established that the use of boehmite as an additive in cements leads to an increase in the strength properties of concrete and increase its frost resistance, which is a prerequisite for long-term and reliable operation of the composite solution. Thus, the composite solution modified by boehmite is the basis for the creation of plugging solutions
\end{abstract}

\section{Introduction}

Concrete is the most popular building material of the 21st century. Environmental protection and modern environmental requirements require the development of new types of concrete with a given set of properties. In the Strategy of Innovative Development of the Russian Federation, nanotechnologies and composite materials are considered as the main directions.

For the waterproofing of tunnels and the uniform distribution of space between the lining of tunnels and rock, composite injection solutions are used. Due to the growth of scope of grouting work in the northern regions, specific problems related to the strengthening of soils in permafrost have become urgent. Conventional injection solutions

\footnotetext{
* Corresponding author: $012340 @$ email.ru
} 
are of little use, since in permafrost they do not adhere well and have a reduced rate of hydration, even with the introduction of accelerating agents such as calcium chloride.

In order to full realization the potential of cement, traditionally to control the formation of the structure and properties of cement stone, nanoadditives are used, which use byproducts of industry, which is economically justified and contributes to the improvement of the ecological situation. At the same time, the performance characteristics of the resulting materials are improved, such as the strength, crack resistance and durability, meaning the maintenance of the required performance properties during the normalized service life, under the influence of the environment.

Since the mechanical strength of injected grouting mortars can change under conditions of temperature change during freezing, in conditions of permafrost it is necessary to control the change in strength properties of composite solutions from porosity, pore type and frost resistance, which is a characteristic of the durability of the material. The structure of porous space of cement stone, determining its frost resistance, depends on the water-cement ratio, the degree of hydration of cement, the conditions of hardening and the fineness of cement grinding.

Of great importance is the protection of building materials and structures from destruction, which ensures the extension of their service life. It is known that the introduction of nanotubes into mortars provides high strength, watertightness, crack resistance and durability of the construction. To improve the physical and mechanical properties of cement composites, the nanoconstruction effect is used, which is possible with the use of nanoparticles with elongated geometry [1-4].

The increase in frost resistance and strength characteristics of cement concretes and solutions modified by carbon nanoparticles is caused by the compaction of their structure, which is noted in the works of domestic and foreign scientists A.N. Ponomareva, V.R. Falikman, V.A. Perfilova, T.A. Nizina, G.I. Yakovleva, I.A. Pudova, A.F. Khuzina, A.V. Yeletsky, M.S. Dresselhaus, T. Kazuyoshi, M.F. Yu, G.Y. Li, De Ibarra, X.J. Xiang, J.M. Makar et al. [5-9]. It is the formation of a larger number of crystalline hydrate neoplasms of increased density and strength and causes a densification of the structure of the cement stone[10-11].

\section{Methods}

Fullerenes, astralenes and carbon nanotubes are most often used as carbon nanoparticles for modifying cement matrices [12].

The polyhedral structure of astralene particles consists of 20-50 flat graphene sheets of average size $\sim 15 \mathrm{~nm}$, connected by edge defect areas, predominantly of a pentagonal structure. Around astralenes there is a starlike "growth" of the cement stone, with further penetration into the thickness of the fillers by an additional nano-polar bond.

Carbon nanotubes (CNTs) - graphene planes folded into tubes [13,14], can be singlelayer (with diameter $\mathrm{d}=1-1.5 \mathrm{~nm}$ ) or multilayered, with a separation between layers of 3.4 $\mathrm{nm}$. The introduction of CNTs makes it possible to increase the strength of the cement composite, to reduce the formation of cracks in the early periods of hardening, to improve the quality of the interface between the phases of the matrix filler $[1,15]$.

The limited introduction of carbon nanoparticles is connected to their propensity for agglomeration and uneven distribution of the volume of the composite cement mixture [1618]. This requires the use of special technologies.

For the production of cement-containing solutions and concretes, nanoadditives and nanomodifiers consisting of nanoparticles, both natural and artificial and technogenic, can be used. Some kinds of industrial waste can be referred to nanotechnogenic raw materials under certain conditions [19], for example, a nanocrystalline powder of aluminum oxides 
and hydroxides. Such a waste is formed with the technology of hydrogen production by burning aluminum and is pure nanocrystalline oxides and aluminum hydroxides, with developed surface structure, and obtaining particles up to ten microns in size.

The aim of the work was to study the increase in strength and frost resistance of grouting mortars made on the basis of cement with the introduction of additive - boehmite, which is a waste of production. During the experiment, M500 cement, modified with bentonite of grade P2T2A, nanocrystalline powder - boehmite, and liquid glass of the brand "TEX" (GOST 13078-81), with water-cement ratio in the composite system of 2:1.

Bemit-orthorhombic crystal structure with elementary cells: $\mathrm{a}=2.87, \mathrm{~b}=12.23, \mathrm{c}=$ $3.70 \AA$ (Figure 1).

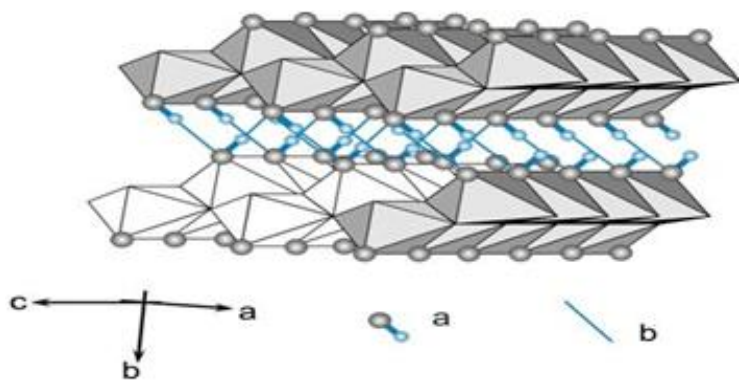

Fig. 1. The structure of boehmite a-OH; b-hydrogen bond.

In it, aluminum ions are surrounded by six oxygen ions, located at the vertices of irregular octahedra. Oxygen ions are bound by the ribs, located at the vertices of irregular octahedra. Oxygen ions are bound by the ribs, with the exception of one of the axes, where they join into double layers with hydrogen bonds, which form zigzag chains. On the one hand, the oxygen anion adjacent to the hydrogen cation is linked to the aluminum cation. On the other hand, the bond is carried out with three hydrogen cations, which leads to a saturation of the valence of the $\mathrm{O}^{2-}$ ion, which is also fully saturated in the double layer by the valence of the four $\mathrm{Al}^{3+}$ cations surrounding it. Therefore, the boehmite structure corresponds to the formula AlOOH. The particle size distribution is shown in Figure 2.

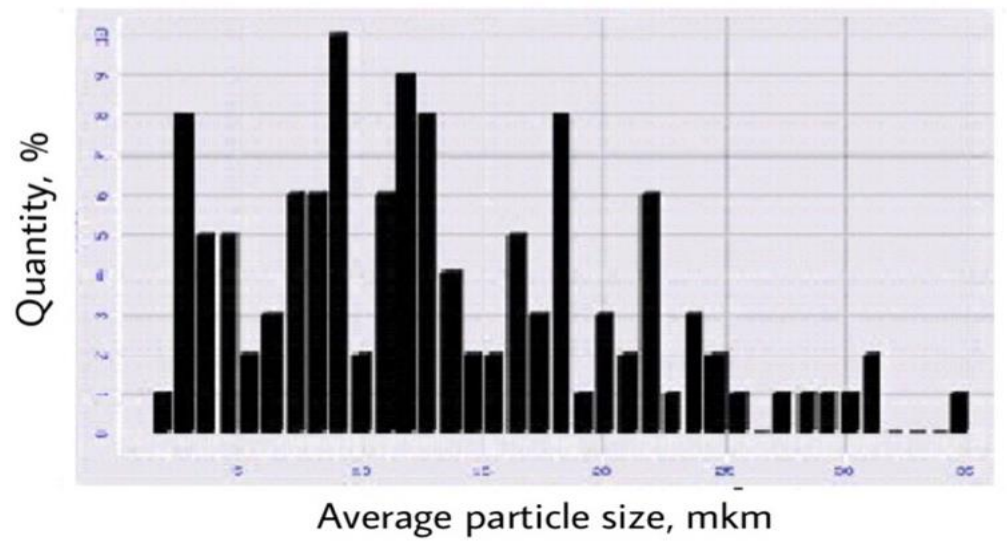

Fig. 2. Distribution of boehmite particles by size. 


\section{Results}

X-ray method revealed the size of crystals: $30-60 \mathrm{~nm}$, with the primary aggregate size of primary particles - 1-3 $\mu \mathrm{m}$, which gives nanosized particles. Therefore, when boehmite is added to the composite system, a dense packing of the cement stone takes place due to the filling of voids. Based on the morphostructural features of the structure of nanoscale particles, boehmite refers to the $3 \mathrm{D}$ nanocrystalline type of substances (3D-NCM nanocrystalline modifier). Based on the x-ray phase analysis (BPA) of boehmite, it was suggested that this modifier has a developed phase interface, and therefore introducing it into the binder will have a significant effect on hydration (Table 1).

Table 1. Physico-chemical indicators of boehmite.

\begin{tabular}{|c|c|c|}
\hline $\begin{array}{l}\text { № } \\
\text { П/ח }\end{array}$ & Description & Value \\
\hline 1 & 2 & 3 \\
\hline 1 & Appearance & Fine powder of white color \\
\hline 2 & Structure of the crystal & Bemit \\
\hline 3 & $\begin{array}{c}\text { The size of the crystallites, nm, (FullProf) } \\
\text { Particle size, nm, (FEC) }\end{array}$ & $\begin{array}{c}10 \\
140\end{array}$ \\
\hline 4 & $\begin{array}{l}\text { Mass fraction of impurities (in terms of } \\
\text { on calcined substance), } \% \text {, not more than: } \\
\text { silicon dioxide }\left(\mathrm{SiO}_{2}\right), \\
\text { iron oxide }\left(\mathrm{Fe}_{2} \mathrm{O}_{3}\right), \\
\text { sodium oxide }\left(\mathrm{Na}_{2} \mathrm{O}\right)\end{array}$ & $\begin{array}{l}0,05 \\
0,05 \\
0,05\end{array}$ \\
\hline 5 & Mass fraction of water, $\%$, not more than & 1,5 \\
\hline 6 & $\begin{array}{c}\text { Specific true density, } \mathrm{g} / \mathrm{cm}^{3} \text {, not more } \\
\text { than }\end{array}$ & 3,06 \\
\hline 7 & Bulk density, $\mathrm{kg} / \mathrm{m}^{3}$, not more than & 600 \\
\hline 8 & Porosity (BET method) - no more than, $\%$ & 30 \\
\hline 9 & $\begin{array}{l}\text { Loss of mass upon calcination (at } \\
\left.\text { temperatures up to } 1100^{\circ} \mathrm{C}\right), \% \\
\text { no more }\end{array}$ & 17 \\
\hline 10 & $\begin{array}{l}\text { Active specific surface area (BET } \\
\text { method) }, \mathrm{m}^{2} / \mathrm{g}\end{array}$ & 55,9 \\
\hline 11 & $\begin{array}{c}\text { Disperse composition by fractions, } \% \text { : } \\
1 \div 5 \mu \mathrm{m} \\
5 \div 10 \mu \mathrm{m} \\
10 \div 20 \mu \mathrm{m} \\
>20 \mu \mathrm{m}\end{array}$ & $\begin{array}{c}55 \\
35 \\
10 \\
0\end{array}$ \\
\hline
\end{tabular}

The main component of the injection solution is cement. The integral and differential particle size distribution and the granulometric composition of M500 cement are presented in Table 2 and in Figure 3. 
Table 2. Granulometric composition of cement.

\begin{tabular}{|l|c|c|c|}
\hline Sample & $\begin{array}{c}\text { Maximum particle size } \\
\mathrm{d} 95, \mu \mathrm{m}\end{array}$ & $\begin{array}{c}\text { Average particle size } \\
\mathrm{d} 50, \mu \mathrm{m}\end{array}$ & $\begin{array}{c}\text { Particle less than } \\
2 \mu \mathrm{m}, \% \text { by mass }\end{array}$ \\
\hline $\begin{array}{l}\text { Cement } \mathrm{M} \\
500\end{array}$ & 56,828 & 15,061 & 12,95 \\
\hline
\end{tabular}
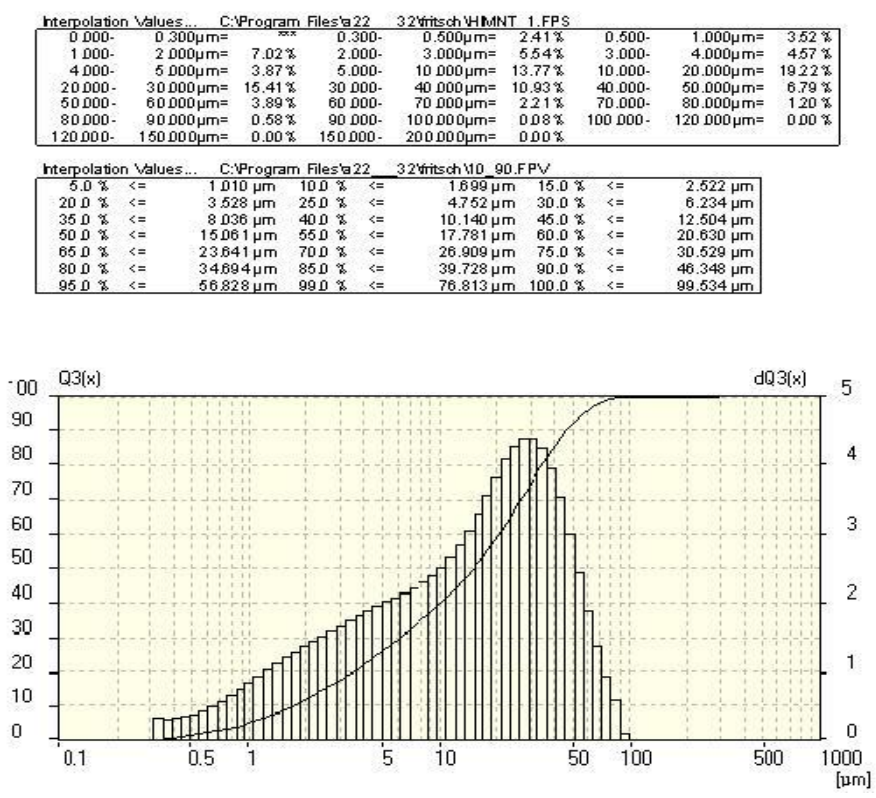

Fig. 3. Integral and differential particle size distribution in a sample of M500 cement.

According to the results obtained, the recycled cement M500 with a specific surface area of $450 \mathrm{~cm}^{2} / \mathrm{g}$ has a predominant particle size of 1 to $90 \mu \mathrm{m}$. About $88 \%$ of the particles have a size of less than $57 \mu \mathrm{m}$, and the rest - less than $2 \mu \mathrm{m}$.

Bentonite $\mathrm{P}_{2} \mathrm{~T} 2 \mathrm{~A}$ contains montmorillonite - 75-80\%, quartz - $15-17 \%$, kaolinite - $1-2 \%$, and mica-muscovite-type hydromica - 1-2\%. The integral and differential particle size distribution and granulometric composition of bentonite are presented in Table 3 and in Figure 4. The granulometric composition of bentonites is presented in Table 3.

Table 3. Granulometric composition of bentonite.

\begin{tabular}{|c|c|c|c|}
\hline Sample & $\begin{array}{c}\text { Maximum particle } \\
\text { size d } 95, \mu \mathrm{m}\end{array}$ & $\begin{array}{c}\text { Average particle } \\
\text { size d 50, } \mu \mathrm{m}\end{array}$ & $\begin{array}{c}\text { Particle less than } 2 \\
\mu \mathrm{m}, \% \text { by mass }\end{array}$ \\
\hline $\begin{array}{c}\text { Bentonite } \\
\mathrm{P}_{2} \mathrm{~T} 2 \mathrm{~A}\end{array}$ & 12,270 & 2,969 & 34,23 \\
\hline
\end{tabular}




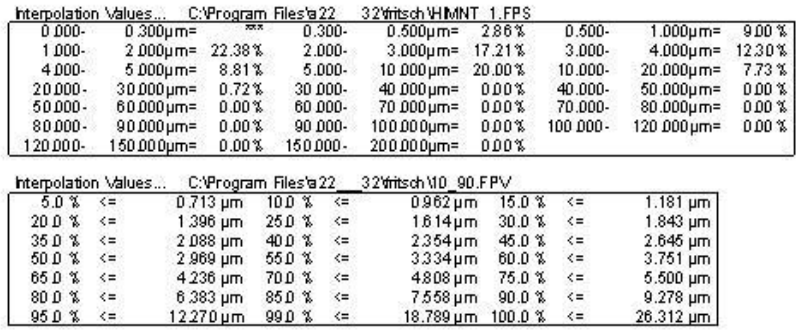

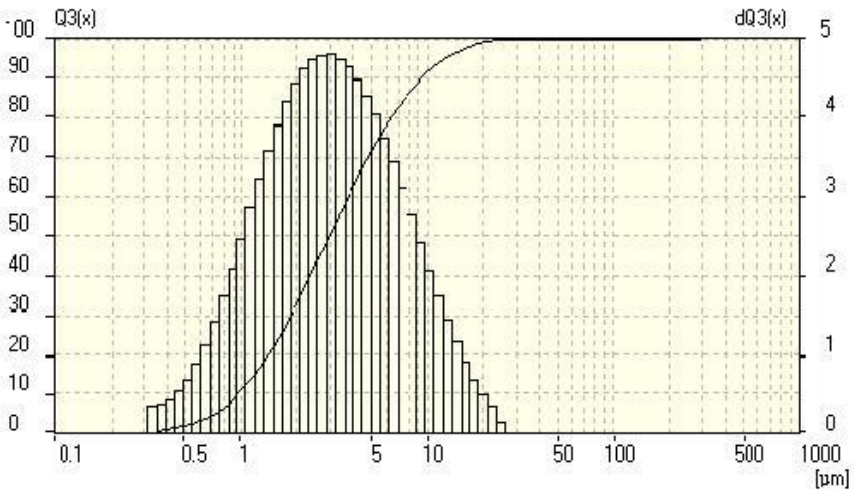

Fig. 4. Integral and differential particle size distribution in bentonite.

It has been found that bentonite has a specific surface area of $290 \mathrm{~cm}^{2} / \mathrm{g}$ and a predominant particle size in the range of 1 to $10 \mu \mathrm{m}$. Moreover, $66 \%$ of the powder particles have a particle size of less than $12 \mu \mathrm{m}$, and only $34 \%$ of the particles are less than $2 \mu \mathrm{m}$.

To reduce the time of setting, liquid glass (GOST13078-81) - universal, brand TEX - was introduced. In the composite system the water-cement ratio was 2:1. To prepare the composite solution, the mixture was first made by dry mixing of cement, bentonite with boehmite additives, then water was added and, mixing at $600 \mathrm{rpm}$, and $5 \%$ water glass to the weight of the mixture.

In previous studies it was established that after 28 days of storage the maximum rate of the process of structure formation is achieved when the optimal concentration of boehmite is $0.208 \%$ to the mass of cement (Figure 5). Compared to the control sample, the rate of structure formation increases almost 1.2 times.

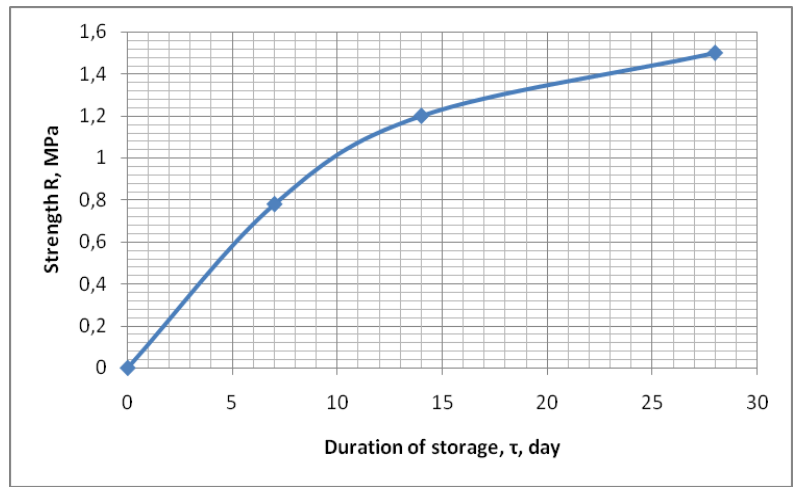

Fig. 5. Structurization of a composite solution with an optimal adding of boehmite. 


\section{Discussion}

For the frost resistance test, samples were prepared: cubes $70 \times 70 \mathrm{~mm}$, made from a composite composition containing boehmite (W6 on the composition selection chart), and stored for up to 28 days in a normal hardening chamber ( 6 samples). The frost resistance of the samples was determined by repeated freezing and thawing (in accordance with GOST 10060-2012 and GOST 5802-86), accelerated by the method of $5 \% \mathrm{NaCl}$ solution at minus temperature $(25 \pm 50 \mathrm{C})$. Tests of strength samples were carried out in accordance with GOST 10180-2012 on the press IP-1A-1000 (certificate of verification No.AA 2217924 until 09.07.2016). A sample saturated with $\mathrm{NaCl}$ solution was placed in a dilatometer and held for 30 minutes, then placed in a freezer and frozen at a temperature drop of minus (25 $\pm 5^{\circ} \mathrm{C}$ ) at a rate of $0.3^{\circ} \mathrm{C} / \mathrm{min}$. Frost resistance of the brand of the mixture was determined by (in accordance with GOST 10060.3-95). On the basis of the graph of the dependence of the maximum relative difference between the volume deformations of the cured composite solution and the standard sample on the freezing temperature, (Table 4).

Table 4. Effect of boehmite additive in the composite mixture on frost resistance.

\begin{tabular}{|c|c|c|c|c|c|c|}
\hline $\begin{array}{c}\text { Characteristics of } \\
\text { the sample }\end{array}$ & $\begin{array}{c}\text { Freezing, } \\
\text { cycles }\end{array}$ & \multicolumn{2}{|c|}{$\begin{array}{c}\text { Compressive strength, } \\
\mathrm{MPa}\end{array}$} & $\begin{array}{c}\text { Loss of } \\
\text { strength, } \%\end{array}$ & $\begin{array}{c}\text { Mass } \\
\text { loss, \% }\end{array}$ & $\begin{array}{c}\text { Frost } \\
\text { resistance, } \\
\text { F }\end{array}$ \\
\cline { 3 - 4 }
\end{tabular}

To determine frost resistance, the method of alternating freezing and thawing of samples is applied. The criterion for frost resistance of cement stone is the number of cycles when the loss of mass of the sample is less than 5\%, and the reduction in strength should not be more than $25 \%$ of the original value.

The loss of strength of the composite solution with the addition of boehmite does not exceed $1 \%$, and the mass loss through 100 cycles of freezing and thawing is 0.4 . Frost resistance of the modified composite solution corresponds to the brand F100. This proves that the addition of nanoadditives to cement leads to more intensive hydration of cement, increasing the density of cement stone [20-21].

\section{Conclusion}

1. Experimental studies have established that the use of boehmite as an additive in cements leads to an increase in the strength properties of concrete.

2. As a result of the experiments carried out, it was noted that the frost resistance of concrete based on the proposed composite portland cement with the addition of boehmite is higher than for the control composition, which is a prerequisite for a long and reliable operation of the composite solution

3. Frost resistance of concrete is enhanced by modifying the cement stone with a new boehmite additive. This allows you to influence the formation of the structure and phase composition of the cement stone. Thus, the composite solution modified by boehmite is the basis for the creation of oil wells. 


\section{References}

1. G.I. Yakovlev, G.N. Pervushin, A.F. Burianov, V.I. Kodolov, Building Materials, 3, 99 (2009)

2. M.N. Vauchsky, Building: new technologies, new equipment, 2, 47 (2009)

3. I. Campillo, et al., Proceedings of the 1st international symposium on nanotechnology in construction (NIKOM 2003). 215 ( 2004)

4. L. Raki, J.J. Beaudoin, R. Alizadeh, J.M. Makar, T. Sato, Materials., 3, 918 (2010)

5. T.A. Nizina, S.N. Kochetkov, A.N. Ponomarev, A.A. Kozeev, Regional architecture and construction, 1 , 43 (2013)

6. A.N. Ponomarev, Problems of Material Science 3, 49 ( 2003)

7. Pudov, I.A. Nanomodification of portlandcement with aqueous dispersions of carbon nanotubes: dis. ... cand. tech. Sciences: 05.23.05 / Pudov Igor Alexandrovich. - Kazan, 2013, $185 \mathrm{P}$.

8. Khuzin, A.F. Cement composites with additives of multilayered carbon nanotubes: dis. ... cand. tech. Sciences: 05.23.05 / Khuzin Ayrat Faritovich. - Kazan, 2014,182 P.

9. T. Kazuyoshi, Y. Tokio, F. Kenichi, Elsevier, 206 (1999)

10. M.N. Vauchsky, The Bulletin of Civil Engineers, 2, 2 (3), 44 (2005)

11. S.S. Kiski, I.V. Ageev, 8, 42 (2012)

12. M. Panfilova1, N.Zubrev, V. Kashintseva, 12, 13, 3616 (2017)

13. Pat. 2196731 Russian Federation, IPC6 From 04 to 28/02. Polyhedral multilayer carbon nanostructures of fulleroid type / A.N. Ponomarev, V.A. Nikitin. - No. 2000124887A; claimed. 21.09.2000; publ. 20.01.2003, - 9 p.

14. M.E. Yudovich, A.N. Ponomarev, S.I. Gareev, 3, 44 (2008)

15. S.V. Bulyarsky. - Ulyanovsk: Strezhen LLC, 478 (2011)

16. M.S. Konsta-Gdoutos, et al., Cement and Concrete Research, 40, 1052 (2010)

17. J. Makar, J. Beaudoin, et. al., Proceedings of the 1 st international symposium on nanotechnology in construction (NIKOM 2003), 331 (2004)

18. R. Saito, M.S. Dresselhaus, G. Dresselhaus, World scientific NY, 272 (1998)

19. E.A. Karpova, A.E. Mohamed, G. Skripkyunas, J. Keren, et al., Building Materials, 2, 40 (2015)

20. V.V. Strokova, A.B. Bukhalo Building materials, 1, 38 (2008)

21. M.V. Ustinova, N.I. Zubrev, M.I. Panfilova, O.V. Novoselova, S.Y. Efremova, M.A. Zhuravleva, Ecology and industry Rossiit, 22, 5, 36 (2018) 